\title{
Coping strategies of women with postpartum depression symptoms in rural Ethiopia: a cross-sectional community study
}

Telake Azale ${ }^{1,2}$, Abebaw Fekadu ${ }^{2,3}$, Girmay Medhin ${ }^{4}$ and Charlotte Hanlon ${ }^{2,5^{*}}$ (D)

\begin{abstract}
Background: Most women with postpartum depression (PPD) in low- and middle-income countries remain undiagnosed and untreated, despite evidence for adverse effects on the woman and her child. The aim of this study was to identify the coping strategies used by women with PPD symptoms in rural Ethiopia to inform the development of socio-culturally appropriate interventions.
\end{abstract}

Methods: A population-based, cross-sectional study was conducted in a predominantly rural district in southern Ethiopia. All women with live infants between one and 12 months post-partum $(n=3147)$ were screened for depression symptoms using the validated Patient Health Questionnaire, 9 item version (PHQ-9). Those scoring five or more, 'high PPD symptoms', $(n=385)$ were included in this study. The Brief Coping with Problems Experienced (COPE-28) scale was used to assess coping strategies. Construct validity of the brief COPE was evaluated using confirmatory factor analysis.

Results: Confirmatory factor analysis of the brief COPE scale supported the previously hypothesized three dimensions of coping (problem-focused, emotion-focused, and dysfunctional). Emotion-focused coping was the most commonly employed coping strategy by women with PPD symptoms. Urban residence was associated positively with all three dimensions of coping. Women who had attended formal education and who attributed their symptoms to a physical cause were more likely to use both problem-focused and emotion-focused coping strategies. Women with better subjective wealth and those who perceived that their husband drank too much alcohol were more likely to use emotion-focused coping. Dysfunctional coping strategies were reported by women who had a poor relationship with their husbands.

Conclusions: As in high-income countries, women with PPD symptoms were most likely to use emotion-focused and dysfunctional coping strategies. Poverty and the low level of awareness of depression as an illness may additionally impede problem-solving attempts to cope. Prospective studies are needed to understand the prognostic significance of coping styles in this setting and to inform psychosocial intervention development.

\section{Background}

Postpartum depression (PPD) is a major public health concern in low and middle income countries (LMICs) [1]. PPD is the most common mental health problem in the perinatal period, with a weighted mean prevalence estimate of $19.8 \%$ (95\% confidence interval 19.5 to $20.0 \%$ ) in community studies from LMICs [2]. Risk factors for PPD in LMICs are mostly social stressors, including poverty, poor social

\footnotetext{
* Correspondence: charlotte.hanlon@kcl.ac.uk

${ }^{2}$ Addis Ababa University, Department of Psychiatry, School of Medicine,

College of Health Sciences, 9086 Addis Ababa, PO, Ethiopia

${ }^{5}$ King's College London, Institute of Psychiatry, Psychology and Neuroscience, Centre for Global Mental Health, London, UK

Full list of author information is available at the end of the article
}

support, intimate partner violence, history of pregnancy loss and unintended pregnancy, all of which tend to be common in LMICs [2]. Evidence for a negative impact of PPD in LMICs is accumulating [3]. Many studies have shown that the children of depressed mothers are more likely to be undernourished [4], although evidence from sub-Saharan Africa is conflicting [5-7]. Increased risk of infant diarrheal episodes has been found in Ethiopia [8] and Pakistan [9], and increased infant mortality associated with maternal depression has been shown in Ethiopia [10] and Ghana [11]. Adverse effects of maternal depression on child development have been found in India [12] and Bangladesh [13], with conflicting reports from Ethiopia [5, 14]. Despite 
these adverse effects, PPD in women in LMICs mostly remains undetected and untreated.

There is a global initiative to integrate mental health services into maternal health care [15]. The World Health Organization has identified evidence-based packages of care for depression and other priority mental disorders which can be delivered by general health workers [16]. Given the challenges associated with safety and acceptability of psychotropic medicines in the perinatal period, there is a need for contextually appropriate psychosocial interventions $[17,18]$. There is burgeoning evidence for effective psychosocial interventions for PPD that can be provided by non-mental health professionals in middle-income countries [19-21], but little from rural, low income country settings. Adaptation and successful implementation of a psychosocial intervention requires an understanding of women's existing coping mechanisms within that context.

Coping is described as the cognitive and behavioral processes that a person uses to deal with stressful circumstances that are judged to be demanding, challenging, threatening and/or have a potential for harm or loss [22]. Coping styles have been categorized into three dimensions: problem-focused, emotion-focused and dysfunctional or avoidance coping [22, 23]. Problem-focused coping involves dealing with the source of stress, while emotion focusedcoping is when the person attempts to handle thoughts and feelings associated with the stressor [22]. Avoidance or dysfunctional coping refers to strategies which avoid dealing with either the problem or the associated emotions [23]. The choice of coping strategies also depends on the nature of the stressor, the person's perception of the seriousness of the experience and his/her evaluation of the resources available for coping and the likely effectiveness of a given strategy [22]. The negative cognitive biases and self-concept seen in individuals with depression may weaken their use of adaptive coping strategies and thereby influence outcome [24]. In support of this, associations have been found between coping strategies and the onset, course and outcome of depression in high-income countries [25]. People with depression are more likely to use avoidance coping strategies $[25,26]$. Problem solving and emotion-focused coping are associated with less severe symptoms, while venting emotions (a dysfunctional strategy) has been associated with more impairment in functioning [27].

Coping strategies vary across cultures [28, 29]. There have been few studies examining the association between perinatal depression and coping strategies. Perinatal depression has been associated with emotion-focused coping in Greece [30] and with avoidance or dysfunctional coping in Belgium [31], Spain [32] and Greece [33]. In a study from a middle-income country, Brazil, an association was found between PPD and avoidance coping [34]. A study of coping among Ethiopians displaced from Eritrea found that both women and those who experienced traumatic events used emotion-focused coping more frequently, although female sex and better social support were associated with problem-focused coping [35].

The lack of evidence on coping strategies employed by women with PPD in a rural, low-income country setting, like Ethiopia, is a barrier to scaling up appropriate care. In Ethiopia and four other LMICs, the PRogramme for Improving Mental health carE (PRIME) is working to integrate maternal mental health services into primary health care. The aim of the current study was to assess the specific coping strategies used by women with symptoms of PPD in a rural Ethiopian setting with a view to informing development of appropriate interventions.

\section{Methods}

Study design

A population-based cross-sectional survey.

\section{Study area}

The study was conducted in Sodo district, Gurage Zone, Southern Nations, Nationalities and Peoples' Region (SNNPR) of Ethiopia. Sodo is located about $100 \mathrm{~km}$ south of the capital city, Addis Ababa. In the most recent census, the population was estimated to be 161,097 (79,896 male and 81,201 female) [36]. About $85 \%$ of the population lives in a rural setting. Amharic is the official language of the region but is the second language for the majority of inhabitants. Within Sodo district, there are eight primary care health centers, each linked to health posts which are staffed by community-based health extension workers.

The nearest psychiatric out-patient service is located in Butajira town, 30 to $50 \mathrm{~km}$ away. At the time of the study there was no specialist mental health professional located within the district. As part of the PRogramme for Improving Mental health carE (PRIME) [37], health centre staff, including midwives, were given brief inservice training to deliver mental health care in the primary care setting, supported by periodic supervision by a psychiatric nurse. At the time of data collection, the new service was not yet operational.

\section{Sampling}

A population census was conducted by the PRIME project. The census was used to identify women with infant children ( $<1$ year of age). To augment this strategy, a list of immunized infants was obtained from a registry maintained by the health extension workers. As a further strategy, data collectors, who had been recruited from the local community, went house to house to identify any additional eligible women. A total of 3147 eligible women were identified. As part of an interview assessment (described below), all women were screened for PPD symptoms using the Patient Health Questionnaire (PHQ-9). Those scoring above the 
validated cut-off indicating depression ('high PPD symptoms') were included in the study. The eligibility criteria were as follows:

women between one and 12 months postpartum, able to converse in Amharic (the official language of the region) and not acutely unwell.

\section{Data collection}

Data were collected using a structured questionnaire that included socio-demographic, obstetric, psychosocial and behavioral variables. Data collectors $(n=36)$ were trained for nine days and interviewed women in their homes. Four supervisors were also trained and assisted by the investigators. The data collectors were recruited from the district and the sub-districts or, in cases where eligible persons were not available at the specific sub-district, from the neighboring sub-districts. A pretest was conducted in three sub-districts of another district near the study area.

Each household containing an eligible woman was visited by a data collector who then explained the purpose of the research and gave the woman an information sheet or read the information aloud for those who were unable to read. Women who consented to participate were interviewed at a time and place that was convenient for them. Following screening with PHQ-9, those women scoring 5 or more were administered additional questionnaires. Data were collected between April and June 2014.

\section{Measures}

\section{Coping strategies}

In this study we used the Brief COPE Scale [38] to measure coping strategies. The brief COPE is a shortened version of the COPE scale, and has been used widely, including in LMICs.

In validation studies, the Brief COPE Scale was found to have reasonable reliability and validity [39-46]. Although the brief COPE has been used in more than 400 studies, it has rarely been used to assess coping in people with depression. For example, a systematic review of 80 studies that used the Brief COPE revealed that none of the studies was on people with depression [47].

The Brief COPE was originally developed to measure coping with any stressor [38]. The scale has 28 items that assess the degree to which a respondent utilizes a specific coping strategy. The 28 items have been categorized into 14 coping strategies named as: active coping, planning, positive reframing, acceptance, humor, religion, using emotional support, using instrumental support, self-distraction, denial, venting, substance use, behavioral disengagement and self-blame [38] and three higher order categories known as problemfocused, emotion-focused [22, 23], and avoidance or dysfunctional coping [23]. Alternatively, the brief COPE items have been categorized into "adaptive" and "maladaptive" coping. The development of these sub-scales was conceptually driven, and the theoretical grouping of the items to their sub-scales was largely established using principal components analysis [23]. Respondents rate items on a 4-point Likert scale, ranging from 1 "I haven't been doing this at all" to 4 "I've been doing this a lot". As most of the participants were not literate, the items were rephrased into questions so that the questionnaire became interviewer administered. For example, "have you been turning to work or other activities to take your mind off things?" for I have been turning to work or other activities to take my mind of things.

PPD was measured using the Patient Health Questionnaire (PHQ-9) [48]. This instrument was developed to measure depression in the Primary Health Care (PHC) setting. The PHQ-9 has been culturally validated for use in several African country settings [49-53], including postpartum women in a rural setting in Ghana [54], and in the primary health care context in rural Ethiopia [55]. In Ethiopia, a score of five or more was found to have a sensitivity of $83 \%$ and specificity of $75 \%$ for the detection of major depressive disorder.

Explanatory models for PPD symptoms were measured with the Short Explanatory Model Interview (SEMI) [56]. The woman's perception of causes, severity, treatment need and options for symptoms of PPD were assessed by asking open-ended questions and coding the responses using pre-specified categories which had been adapted for the socio-cultural context in Ethiopia. Perceived severity of the condition was coded using the following categories: unable to say, not at all serious, mildly serious, moderately serious or very serious.

Disability was measured using the World Health Organization Disability Assessment Schedule (WHODAS) [57]. Disability was measured in six domains of functional impairment, including understanding and communicating, getting around, self-care, getting along with people, life activities, and participation in society. Scores were from 1 (no difficulty) to 5 (extreme or cannot do). The instrument has been used previously in perinatal women in a rural Ethiopian setting and found to have convergent validity with depressive symptoms [58].

Social support was measured using the Oslo Social Support Scale (OSSS-3) [59], which measures strength of social support. Scores from 3 to 8 indicate poor support, scores from 9 to 11 intermediate support, and a score between 12 and 14 is considered indicative of strong social support. The OSSS-3 has been used in community studies in Ethiopia previously [60].

The following potential confounders were measured using questions which have been used previously in postnatal women in the neighboring district: educational level, perceived relative wealth and hunger due to lack of resources in the past month (socio-economic status), quality of marital relationship, perception that the husband drank too much alcohol or chewed too much khat, and rural or urban residence. 


\section{Data management and analysis}

Data were double entered using EpiData version 3.1 and then exported to SPSS version 20, cleaned, coded and analyzed. Descriptive analyses were carried out, including frequencies, mean and standard deviation and correlations among the items and sub-scales of the Brief COPE. Frequencies of the 28 items of the Brief COPE scale were calculated into the four Likert categories. The internal consistencies of the higher order scales were calculated with Cronbach's alpha. Confirmatory factor analysis was carried out to confirm the recommended three dimensions of coping namely, problem-focused, emotion-focused, and dysfunctional or avoidant coping $[22,61]$ using STATA 12 and AMOS-23 software. The most frequently used model fit indices include chi-square, root mean square error of approximation (RMSREA), comparative fit index (CFI), and Tucker-Lewis Index (TLI). Although there is no agreement as to the acceptable values of the indices, values closer to 1 are considered good fit if TFI and CLI. A value closer to zero is better for RMSEA. The chi-square test is frequently used as an index of model fit. A smaller chi-square value which is insignificant at $p=0.05$ is considered to be a good fit. However, the value of chi-square is affected by several factors, such as sample size, the number of variables, and distribution of variables. Hence it is said to not be a good index practically. This is the reason for the use of alternative indices [62].

The 28 items of the Brief COPE scale were summed into 14 subscales after confirmatory factor analyses. Simple and multiple linear regression analyses were then carried out to examine factors associated with each of the three dimensions of coping. A priori confounders were included in the model, as described above. Other items of exploratory interest, e.g. from the SEMI, were included in the multivariable model if the univariate association with coping strategies had $p<0.2$ ).

\section{Ethical considerations}

Ethical approval was obtained from the Institutional Review Board (IRB) of the College of Health Sciences, Addis Ababa University. Permission letters were received from the district health and administrative offices. Eligible women were given information sheets and those who agreed to participate signed or gave their finger prints before they were interviewed. Women who expressed suicidal ideation were put in contact with mental health care.

\section{Results}

There was a $100 \%$ response rate in the women screened for PPD symptoms. A total of 385 women with a PHQ-9 score of 5 or more were included in the analyses. The percentage of women with high PPD symptoms was, therefore, $12.2 \%(385 / 3147)$. One woman was excluded due to probable psychotic symptoms.

\section{Socio-demographic and psychosocial characteristics}

The mean PHQ score of the participants was 7.8 (Standard Deviation (SD): 3.03). The mean age of the respondents was 28.8 years with 5.23$)$ standard deviation. More than half $(n=$ 232; 60.3\%) of the respondents were between 25 and 34 years of age. Almost all, $(n=374 ; 97.1 \%)$ were married. Three hundred and sixty-three women $(94.3 \%)$ were rural residents. More than two-thirds, $(n=271 ; 70.4 \%)$ were unable to read and write. The vast majority, $(n=365 ; 94.8 \%)$ of the respondents were followers of Orthodox Christianity and 353 (91.7\%) were Gurage by ethnicity. See Table 1.

\section{Coping strategies}

Religious coping was the most frequently used strategy. The two items: "I have been praying or meditating" and "I have been trying to find comfort in my religion or spiritual beliefs" were reported to be used 'a lot' by $49.9 \%(n=192)$ and $36.4 \%(n=140)$ respondents, respectively. The least frequently used coping strategies were substance use $(n=$ $8 ; 2.1 \%)$ and humor $4.2 \%(n=16)$. See Table 2.

Scores on the problem-focused coping sub-scale ranged from six to 24, with a mean of 14.6 (SD 3.95). The emotion-focused coping score ranged from 10 to 40, with a mean of 21.4 (SD 5.41). Dysfunctional coping scores ranged from 12 to 48 with a mean of 22.6 (SD 6.07).

\section{Construct validity of the brief COPE}

The internal consistency of each sub-scale was good, with Cronbach's alpha between 0.72 and 0.74 . In the confirmatory factor analysis, the coefficients for items loading onto the three dimensions of coping ranged from 0.38 for substance use (I have been using alcohol or other drugs to help me get through it) to 0.82 for self-blame (I have been blaming myself for things that happened) and religion (I have been trying to find comfort in my religion or spiritual beliefs). The inter-item correlations were all significant except for the religion and humor items. The three higher order categories (problem-focused, emotion-focused and dysfunctional coping) were highly correlated. The CFA model fit indices were as follows: CMIN/DF 3.58, root mean squared error of approximation (RMSEA) 0.02, the comparative fit index 0.72, and Tucker Lewis Index 0.65. Removing the items with low coefficients did not improve the model fit. Therefore, all items were retained for further analysis. (See Additional file 1).

\section{Factors associated with problem-focused coping}

In the univariate analysis, urban residence, formal education, better relative wealth and attribution of symptoms to a physical cause were all associated significantly with higher scores on the problem-focused coping sub-scale. Not knowing the cause of the illness was associated with significantly lower problem-focused coping scores. 
Table 1 Socio-demographic and psychosocial characteristics of women with symptoms of postpartum depression, Sodo district, $2014(n=385)$

\begin{tabular}{|c|c|}
\hline Socio-demographic characteristic & Frequency \\
\hline \multicolumn{2}{|l|}{ Age (in years) } \\
\hline Less than 20 & $28(7.3)$ \\
\hline $20-29$ & $174(45.2)$ \\
\hline $30-39$ & $175(45.5)$ \\
\hline 40 or above & $8(2.1)$ \\
\hline \multicolumn{2}{|l|}{ Marital status } \\
\hline Married & $374(97.1)$ \\
\hline Single/widowed/divorced & $11(2.9)$ \\
\hline \multicolumn{2}{|l|}{ Residence } \\
\hline Rural & $363(94.3)$ \\
\hline Urban & $22(5.7)$ \\
\hline \multicolumn{2}{|l|}{ Education } \\
\hline No formal education & $308(80.0)$ \\
\hline Formal education & $77(20.0)$ \\
\hline \multicolumn{2}{|l|}{ Religion } \\
\hline Orthodox & $365(94.8)$ \\
\hline Protestant & $12(3.1)$ \\
\hline Muslim & $6(1.6)$ \\
\hline Other & $2(0.6)$ \\
\hline \multicolumn{2}{|l|}{ Ethnicity } \\
\hline Gurage & $353(91.7)$ \\
\hline Oromo & $26(6.8)$ \\
\hline Amhara & $5(1.3)$ \\
\hline Other & $1(0.3)$ \\
\hline \multicolumn{2}{|l|}{ Psychosocial characteristics } \\
\hline \multicolumn{2}{|l|}{ Hunger in the past one month } \\
\hline No & $259(67.3)$ \\
\hline Yes & $126(32.7)$ \\
\hline \multicolumn{2}{|l|}{ Relative wealth } \\
\hline Less & $171(44.4)$ \\
\hline Same & $198(51.4)$ \\
\hline Better & $16(4.2)$ \\
\hline \multicolumn{2}{|l|}{ Social support } \\
\hline Poor & $104(27.0)$ \\
\hline Intermediate & $187(48.6)$ \\
\hline Strong & $94(24.4)$ \\
\hline \multicolumn{2}{|l|}{ Husband drinks too much } \\
\hline No & $290(75.3)$ \\
\hline Yes & $95(24.3)$ \\
\hline \multicolumn{2}{|l|}{ Quality of marital relationship } \\
\hline Bad & $80(20.8)$ \\
\hline Good & $305(79.2)$ \\
\hline
\end{tabular}

Table 1 Socio-demographic and psychosocial characteristics of women with symptoms of postpartum depression, Sodo district, $2014(n=385)$ (Continued)

\begin{tabular}{ll}
\hline Socio-demographic characteristic & Frequency (\%) \\
\hline Perceived cause of postpartum depression symptoms & \\
Psychosocial & $231(60.0)$ \\
Physical & $89(23.1)$ \\
Supernatural & $16(4.2)$ \\
Don't know & $49(12.8)$ \\
Perceived severity of PPD symptoms & \\
Mild & $81(21.0)$ \\
Moderate & $151(39.2)$ \\
Severe & $153(39.8)$ \\
WHODAS score (Disability) & \\
None & $28(7.3)$ \\
Mild & $212(55.1)$ \\
Moderate & $126(32.7)$ \\
Severe & $18(4.7)$ \\
Extreme or cannot do & $1(0.3)$ \\
\hline
\end{tabular}

All except relative wealth remained significantly associated in the multivariable model. See Table 3.

\section{Factors associated with emotion-focused coping}

Urban residence, formal education, better wealth, perception that her husband drank too much alcohol, and perceived physical cause for the symptoms were associated positively with emotion-focused coping in both the simple and multivariable linear regression analyses. Not knowing the cause of the illness and WHODAS score were negatively associated with emotion-focused coping. See Table 4.

\section{Factors associated with avoidance/dysfunctional coping} Urban residence, better wealth, perception that her husband drank too much alcohol and bad marital relationship were positively associated with dysfunctional coping. Not knowing the cause of illness, and WHODAS score were negatively associated with dysfunctional coping in the simple linear regression. Relative wealth and perception that the husband drank too much alcohol were no longer significant in the multivariate analysis. See Table 5.

\section{Discussion}

In this community-based study from a rural, low-income country setting, women with PPD were found to be most likely to use religious and emotion-based coping strategies. Higher scores on emotion- and problembased coping were associated with higher educational level, socio-economic status, urban residence and physical attribution to the symptoms. Dysfunctional coping was associated with marital problems. Emotion-based 
Table 2 Frequency of use of coping strategies by women with symptoms of PPD ( $n=385)$

\begin{tabular}{|c|c|c|c|c|}
\hline Coping strategies & Mean(SD) & Not at all or a little bit & A medium amount & A lot \\
\hline \multicolumn{5}{|l|}{ Emotion-focused coping strategies } \\
\hline I've been praying or meditating. & $2.24(0.83)$ & $96(24.9)$ & $97(25.2)$ & $192(49.9)$ \\
\hline I've been trying to find comfort in my religion or spiritual beliefs. & $1.95(0.87)$ & $156(40.5)$ & $89(23.1)$ & $140(36.4)$ \\
\hline I've been getting comfort and understanding from someone. & $1.84(0.84)$ & $171(44.4)$ & $102(26.5)$ & $112(29.1)$ \\
\hline I've been accepting the reality of the fact that it has happened. & $1.48(0.76)$ & $261(67.8)$ & $61(15.8)$ & $63(16.4)$ \\
\hline I've been looking for something good in what is happening. & $1.46(0.75)$ & $269(69.9)$ & $54(14)$ & $62(16.1)$ \\
\hline I've been trying to see it in a different light, to make it seem more positive. & $1.44(0.74)$ & $273(70.9)$ & $53(13.8)$ & $59(15.3)$ \\
\hline I've been learning to live with it. & $1.37(0.67)$ & $284(73.8)$ & $59(15.3)$ & $42(10.9)$ \\
\hline I've been making jokes about it. & $1.10(0.42)$ & $361(93.8)$ & $8(2.1)$ & $16(4.2)$ \\
\hline I've been making fun of the situation. & $1.12(0.42)$ & 359(93.2) & $10(2.6)$ & $16(4.2)$ \\
\hline \multicolumn{5}{|l|}{ Problem-focused coping strategies } \\
\hline I've been taking action to try to make the situation better. & $1.79(0.82)$ & $178(46.2)$ & $109(28.3)$ & $98(25.5)$ \\
\hline I've been trying to get advice or help from other people about what to do. & $1.65(0.82)$ & $219(56.9)$ & $78(20.3)$ & $88(22.9)$ \\
\hline $\begin{array}{l}\text { I've been concentrating my efforts on doing something about the } \\
\text { situation I'm in. }\end{array}$ & $1.63(0.80)$ & $222(57.7)$ & $82(21.3)$ & $81(21)$ \\
\hline I've been thinking hard about what steps to take. & $1.67(0.79)$ & $206(53.5)$ & $100(26)$ & $79(20.5)$ \\
\hline I've been trying to come up with a strategy about what to do. & $1.62(0.79)$ & $221(57.4)$ & $88(22.9)$ & $76(19.7)$ \\
\hline I've been getting help and advice from other people. & $1.41(0.71)$ & $276(71.7)$ & $58(15.1)$ & $51(13.2)$ \\
\hline I've been getting emotional support from others. & $1.48(0.78)$ & $269(69.9)$ & $47(12.2)$ & $69(17.9)$ \\
\hline \multicolumn{5}{|l|}{ Avoidance/ dysfunctional coping strategies } \\
\hline I've been turning to work or other activities to take my mind off things. & $1.68(0.87)$ & $288(59.2)$ & $50(13)$ & $107(27.8)$ \\
\hline $\begin{array}{l}\text { I've been doing something to think about it less, such as going to movies, } \\
\text { watching TV, reading, daydreaming, sleeping, or shopping. }\end{array}$ & $1.73(0.86)$ & $207(53.5)$ & $73(19)$ & $105(27.3)$ \\
\hline I've been saying things to let my unpleasant feelings escape. & $1.52(0.77)$ & $250(64.9)$ & $68(17.7)$ & $67(17.4)$ \\
\hline I've been blaming myself for things that happened. & $1.54(0.77)$ & $242(62.9)$ & $76(19.7)$ & $67(17.4)$ \\
\hline I've been criticizing myself. & $1.51(0.76)$ & $253(65.7)$ & $67(17.4)$ & $65(16.9)$ \\
\hline I've been saying to myself "this isn't real". & $1.38(0.70)$ & $287(74.5)$ & $47(12.2)$ & $51(13.2)$ \\
\hline I've been expressing my negative feelings. & $1.37(0.69$ & $291(75.6)$ & $45(11.7)$ & $49(12.7)$ \\
\hline I've been refusing to believe that it has happened. & $1.34(0.69)$ & $300(77.9)$ & $37(9.6)$ & $48(12.5)$ \\
\hline I've been giving up trying to deal with it. & $1.26(0.60)$ & $316(82.1)$ & $37(9.6)$ & $32(8.3)$ \\
\hline I've been giving up the attempt to cope. & $1.21(0.55)$ & $329(85.5)$ & $30(7.8)$ & $26(6.8)$ \\
\hline I've been using alcohol or other drugs to make myself feel better. & $1.08(0.37)$ & $366(95.1)$ & $6(1.6)$ & $13(3.4)$ \\
\hline I've been using alcohol or other drugs to help me get through it. & $1.06(0.31)$ & 369(95.8) & $8(2.1)$ & $8(2.1)$ \\
\hline
\end{tabular}

functioning was also increased in women who perceived their husbands to drink too much alcohol.

Religious coping has been found to be among the most frequently used coping strategy by people with depression and other stressors [47, 63-65]. In Ethiopia, most people affiliate themselves with a religion and, thus, it is consistent that religion emerged as the main resource for coping with symptoms of distress and stressful experiences in this study. Emotional coping, of which religious coping is an example, is usually understood to be employed when a person perceives the problem to be beyond their control
[22]. However, religious coping has been conceptualized as either a mediator or a buffer for depressive symptoms, depending on how it is used by the individual [64-66]. An example of positive religious coping could be looking to God for strength, support or guidance. Negative religious coping on the other hand might involve feeling abandoned or being punished by God [67]. Negative religious coping has been found to be a strong predictor of worsening symptoms of depression [68]. In studies from Poland and Greece, women with symptoms of PPD were found to more often use emotion-focused coping [30, 33]. 
Table 3 Simple and multiple linear regression analysis of factors associated with problem focused coping among women with symptoms of postpartum depression, $(n=385)$

\begin{tabular}{|c|c|c|c|}
\hline & Mean (SD) & Crude $\beta(95 \% \mathrm{Cl})$ & Adjusted $\beta(95 \% \mathrm{Cl})$ \\
\hline Age, mean (SD), 28.8(5.2) & & $-0.00(-0.08,0.07)$ & $0.02(-0.04,0.10)$ \\
\hline \multicolumn{4}{|l|}{ Residence } \\
\hline Rural & $14.4(0.2)$ & Ref & Ref \\
\hline Urban & $17.3(0.7)$ & $2.96(1.28,4.65)$ & $2.39(0.67,4.11)$ \\
\hline \multicolumn{4}{|l|}{ Educational Status } \\
\hline No formal education & $14.2(0.2)$ & Ref & Ref \\
\hline Formal education & $15.8(0.4)$ & $1.53(0.55,2.51)$ & $1.50(0.44,2.56)$ \\
\hline \multicolumn{4}{|c|}{ Hunger in the preceding month } \\
\hline No & $14.7(0.2)$ & Ref & Ref \\
\hline Yes & $14.1(0.3)$ & $-0.63(-1.48,0.20)$ & $-0.47(-1.46,0.50)$ \\
\hline \multicolumn{4}{|l|}{ Subjective relative wealth } \\
\hline Less & $14.0(4.2)$ & Ref & Ref \\
\hline Same & $14.8(3.5)$ & $0.84(0.04,1.65)$ & $0.80(-0.14,1.75)$ \\
\hline Better & $16.5(4.5)$ & $2.53(0.52,4.55)$ & $1.62(-0.36,3.61)$ \\
\hline \multicolumn{4}{|l|}{ Social support } \\
\hline Poor & $14.8(3.9)$ & Ref & Ref \\
\hline Intermediate & $14.0(3.6)$ & $-0.76(-1.71,0.18)$ & $-0.91(-1.86,0.04)$ \\
\hline Strong & $15.2(4.5)$ & $0.32(-0.77,1.42)$ & $-0.18(-1.33,0.95)$ \\
\hline \multicolumn{4}{|c|}{ Husband drinks too much alcohol } \\
\hline No & $14.3(0.2)$ & Ref & Ref \\
\hline Yes & $15.1(0.4)$ & $0.80(-0.11,1.71)$ & $0.90(0.00,1.81)$ \\
\hline \multicolumn{4}{|l|}{ Marital relationship } \\
\hline Bad & $14.9(0.4)$ & Ref & Ref \\
\hline Good & $14.4(0.2)$ & $-0.45(-1.43,0.52)$ & $-0.45(-1.44,0.53)$ \\
\hline PHQ score & & $0.11(-0.02,0.24)$ & $0.12(-0.00,0.25)$ \\
\hline \multicolumn{4}{|l|}{ Perceived cause } \\
\hline Psychosocial & $14.5(3.8)$ & Ref & Ref \\
\hline Physical & $15.6(4.3)$ & $1.13(0.18,2.08)$ & $1.12(0.17,2.07)$ \\
\hline Supernatural & $13.8(3.6)$ & $-0.71(-2.69,1.26)$ & $-0.95(-2.94,1.04)$ \\
\hline Unable to say & $12.9(3.4)$ & $-1.54(-2.75,-0.34)$ & $-1.41(-2.62,-0.21)$ \\
\hline \multicolumn{4}{|l|}{ Perceived severity } \\
\hline Mild & $14.8(3.7)$ & Ref & Ref \\
\hline Moderate & $14.0(3.8)$ & $-0.75(-1.82,-0.31)$ & $-0.61(-1.69,0.46)$ \\
\hline Severe & $14.9(4.2)$ & $0.08(-0.98,1.14)$ & $0.36(-0.74,1.47)$ \\
\hline WHODAS Score & & $-0.05(-0.16,0.04)$ & $-0.09(-0.20,0.01)$ \\
\hline
\end{tabular}

bold type signifies statistical significance at $p<0.05$

The least frequently used coping strategies by women with symptoms of PPD in this study were substance use or humor. This is in keeping with the high endorsement of religious coping strategies [69]. Moreover, the participants of this study are women who are less likely to be frequent alcohol users for sociocultural reasons. The low levels of humor-related coping strategies- may reflect cultural norms, but also that this sample of women had high levels of depressive symptoms.

\section{The brief COPE scale and its construct validity}

Confirmatory factor analysis supported the three dimensions of coping, with high loading values for most of the 
Table 4 Simple and multiple linear regression analysis of factors associated with emotion focused coping among women with symptoms of postpartum depression, $(n=385)$

\begin{tabular}{|c|c|c|c|}
\hline Characteristics & Mean(SD) & Crude $\beta(95 \%$ Cl) & Adjusted $\beta(95 \% \mathrm{Cl})$ \\
\hline Age & & $0.00(-0.09,0.10)$ & $0.04(-0.05,0.15)$ \\
\hline \multicolumn{4}{|l|}{ Residence } \\
\hline Rural & $21.2(0.2)$ & ref & ref \\
\hline Urban & $24.4(1.1)$ & $3.18(0.86,5.50)$ & $2.60(0.28,4.93)$ \\
\hline \multicolumn{4}{|l|}{ Educational Status } \\
\hline No formal education & $21.0(0.3)$ & ref & ref \\
\hline Formal education & $22.9(0.6)$ & $1.91(0.56,3.25)$ & $2.02(0.59,3.46)$ \\
\hline \multicolumn{4}{|l|}{ Hunger } \\
\hline No & $21.6(0.3)$ & ref & ref \\
\hline Yes & $20.8(0.4)$ & $-0.75(-1.91,0.40)$ & $-0.34(-1.69,1.00)$ \\
\hline \multicolumn{4}{|l|}{ Relative wealth } \\
\hline Less & $20.8(5.4)$ & Ref & ref \\
\hline Same & $21.5(5.2)$ & $0.72(-0.37,1.82)$ & $0.74(-0.54,2.03)$ \\
\hline Better & $25.3(6.5)$ & $4.53(1.77,7.28)$ & $3.22(0.53,5.92)$ \\
\hline \multicolumn{4}{|l|}{ Social support } \\
\hline Poor & $21.4(4.4)$ & Ref & ref \\
\hline Intermediate & $20.8(4.9)$ & $-0.56(-1.85,0.73)$ & $-0.56(-1.85,0.72)$ \\
\hline Strong & $22.4(6.9)$ & $1.04(-0.46,2.55)$ & $0.41(-1.13,1.95)$ \\
\hline \multicolumn{4}{|l|}{ Husband drinks too much alcohol } \\
\hline No & $20.9(0.3$ & ref & ref \\
\hline Yes & $22.8(0.6)$ & $1.89(0.64,3.14)$ & $(0.69,3.14)$ \\
\hline \multicolumn{4}{|l|}{ Marital relationship } \\
\hline Bad & $21.8(0.6)$ & ref & ref \\
\hline Good & $21.3(0.3)$ & $-0.59(-1.93,0.74)$ & $-0.52(-1.86,0.81)$ \\
\hline PHQscore (Mean:7.83, SD: 3.03) & & $0.11(-0.06,0.29)$ & $0.15(-0.02,0.33)$ \\
\hline \multicolumn{4}{|l|}{ Perceived cause } \\
\hline Psychosocial & $21.2(4.9)$ & ref & ref \\
\hline Physical & $23.4(6.2)$ & $2.21(0.91,3.50)$ & $2.35(1.06,3.63)$ \\
\hline Supernatural & $21.0(6.2)$ & $-0.18(-2.86,2.50$ & $-0.61(-3.31,2.08)$ \\
\hline Unable to say & 18.9(4.6) & $-2.20(-3.83,-0.56)$ & $-1.96(-3.59,-0.33)$ \\
\hline \multicolumn{4}{|l|}{ Perceived severity } \\
\hline Mild & $21.3(4.9)$ & ref & ref \\
\hline Moderate & $21.1(5.6)$ & $-0.15(-1.62,1.31)$ & $0.09(-1.37,1.55)$ \\
\hline Severe & $21.7(5.4)$ & $0.42(-1.04,1.88)$ & $0.65(-0.85,2.15)$ \\
\hline WHODAS Score & & $-0.13(-0.27,0.00)$ & $-0.16(-0.30,-0.02)$ \\
\hline
\end{tabular}

bold type signifies statistical significance at $p<0.05$

items except the substance use and venting items. The model fit was also fairly good, but fell short of the conventional cut-offs on the indices of model fit. It is possible that some aspects of coping which are relevant in this context were not captured fully by the scale. The Brief COPE scale has been validated in different cultures among women with breast cancer in Malaysia [39] and caregivers of people with dementia in the UK [40]. In both of these studies, the Brief COPE was reported to be valid and reliable. In the first validation study, sensitivity of the scale to change was also indicated, with the Effect Size Index (ESI) ranging from 0 to 0.53. In the second study, high internal consistency and testretest reliability over a year were demonstrated for emotion-focused, problem-focused, and dysfunctional subscales. 
Table 5 Simple and multiple linear regression analysis of factors associated with dysfunctional coping among women with symptoms of postpartum depression, $(n=385)$

\begin{tabular}{|c|c|c|c|}
\hline Characteristics & Mean (SD) & Crude $\beta(95 \% \mathrm{Cl})$ & Adjusted $\beta(95 \% \mathrm{Cl})$ \\
\hline Age & & $0.02(-0.09,0.13)$ & $0.07(-0.04,0.19)$ \\
\hline \multicolumn{4}{|l|}{ Residence } \\
\hline Rural & $22.4(0.3)$ & Ref & Ref \\
\hline Urban & $26.0(1.3)$ & $3.63(1.03,6.23)$ & $4.13(1.50,6.76)$ \\
\hline \multicolumn{4}{|l|}{ Educational Status } \\
\hline No formal education & $22.5(0.3)$ & Ref & Ref \\
\hline Formal education & $22.8(0.7)$ & $0.23(-1.28,1.75)$ & $0.60(-1.02,2.22)$ \\
\hline \multicolumn{4}{|l|}{ Hunger } \\
\hline No & $22.9(0.4)$ & Ref & Ref \\
\hline Yes & $21.9(0.5)$ & $-0.94(-2.23,0.35)$ & $-0.92(-2.45,0.60)$ \\
\hline \multicolumn{4}{|l|}{ Relative wealth } \\
\hline Less & $22.2(5.9)$ & Ref & Ref \\
\hline Same & $22.6(5.8)$ & $0.38(-0.85,1.62)$ & $0.28(-1.17,1.73)$ \\
\hline Better & $25.6(9.5)$ & $3.34(0.23,6.45)$ & $1.72(-1.32,4.77)$ \\
\hline \multicolumn{4}{|l|}{ Social support } \\
\hline Poor & $22.1(5.5)$ & Ref & Ref \\
\hline intermediate & $22.4(5.3)$ & $0.30(-1.15,1.76)$ & $-0.15(-1.61,1.30)$ \\
\hline Strong & $23.4(7.7)$ & $1.25(-0.44,2.95)$ & $0.11(-1.63,1.30)$ \\
\hline \multicolumn{4}{|c|}{ Husband drinks too much alcohol } \\
\hline No & $22.2(0.3)$ & Ref & Ref \\
\hline Yes & $23.8(0.7)$ & $1.65(0.24,3.05)$ & $1.23(-0.14,2.62)$ \\
\hline \multicolumn{4}{|l|}{ Marital relationship } \\
\hline Bad & $24.6(0.6)$ & $2.54(1.06,4.02)$ & $2.94(1.44,4.43)$ \\
\hline Good & $22.0(0.3)$ & Ref & Ref \\
\hline PHQ score & & $0.09(-0.10,0.30)$ & $0.11(-0.09,0.31)$ \\
\hline \multicolumn{4}{|l|}{ Perceived cause } \\
\hline Psychosocial & $22.6(5.7)$ & Ref & Ref \\
\hline Physical & $23.7(7.3)$ & $1.03(-0.44,2.51)$ & $1.39(-0.05,2.84)$ \\
\hline Supernatural & $21.7(5.0)$ & $-0.92(-3.99,2.13)$ & $-0.56(-3.61,2.49)$ \\
\hline Unable to say & $20.6(5.0)$ & $-2.02(-3.88,-0.15)$ & $-1.97(-3.82,-0.13)$ \\
\hline \multicolumn{4}{|l|}{ Perceived severity } \\
\hline Mild & $23.4(5.8)$ & Ref & Ref \\
\hline Moderate & $22.2(6.1)$ & $-1.25(-2.90,0.38)$ & $-0.66(-2.31,0.99)$ \\
\hline Severe & $22.5(6.1)$ & $-0.86(-2.50,0.77)$ & $0.08(-1.62,1.78)$ \\
\hline WHODAS Score & & $-0.32(-0.48,-0.17)$ & $-0.36(-0.53,-0.20)$ \\
\hline
\end{tabular}

bold type signifies statistical significance at $p<0.05$

\section{Factors associated with coping styles}

There were very high correlations among the sub-scales of the COPE in this study, for example 0.98 between problemfocused and emotion-focused coping. The scores on all of the COPE sub-scales, problem-focused, emotion-focused and dysfunctional, were significantly higher for urban residents. Women with formal education were more likely to use both problem- and emotion-focused coping. Urban women may differ from rural women in characteristics such as their access to resources and information, and the way in which they express their feelings, all of which will influence coping styles. Women living in rural areas in Ethiopia are often less empowered than their urban counterparts, for example, more likely to live in a non-consenting marriage [70]. They are likely to have fewer resources for problem-focused coping, less propensity to express their private feelings for 
emotion-focused coping, and may have less personal freedom for dysfunctional coping. Women who perceived that their wealth was better than their neighbors were more likely to use emotion-focused, but not problem-focused, coping. In this rural Ethiopian context, social support is closely linked to a person's capacity to reciprocate; therefore, poverty may undermine the possibility of obtaining emotional support and reframing of women's difficulties [71].

Attribution of the symptoms of postpartum depression to a physical cause was associated with significantly higher scores for both problem and emotion-focused coping. However, being unable to identify a cause for the PPD symptoms was negatively associated with all three dimensions of coping. It follows that if a person does not know what caused their problem, this is likely to be a barrier to effective coping. One possible explanation is that women may not consider their PPD symptoms to be the result of an illness (and, therefore, to be a 'problem'), but rather a part of life experience that they have to accept and live with. Women in LMICs attribute PPD to financial difficulties and marital conflict [72]. Similarly, in Ethiopia, although symptoms of PPD are recognized, they are attributed to social adversity or to failure of carrying out cultural chores that could expose to supernatural attacks which they believe cause the symptoms [73]. The implication of this may be that resources such as knowledge about depression and increasing social support might promote more problemfocused coping and contribute to improving symptoms.

Dysfunctional coping was increased in women who said that their relationship with their husbands was poor. Dysfunctional coping has been reported to be commonly used by people with high emotional distress, for example in the context of marital discord [74, 75]. The perception that their husbands drink too much alcohol was positively associated with emotion-focused coping. Thinking that one's husband drinks too much alcohol may mean it is difficult to modify that behavior. This may lead to the perception of the problem as unsolvable. Those individuals who perceive that their stressor is uncontrollable tend to use either emotion-focused or dysfunctional coping strategies [22]. Women in Ethiopia especially in the rural parts get married at early age without their consent and are economically dependent on their husbands. They are expected to stoically tolerate marital problems and maintain their marriage at all costs. Women who are married at young age are unlikely to have been to school and less likely to have known about the marriage beforehand and more likely to have experienced forced first marital sex and subsequent intimate partner violence [70].

Women who reported more functional impairment (scoring higher on the WHODAS) were less likely to use emotion-focused and dysfunctional coping compared to those with less functional impairment. Furthermore, no association was seen between functional impairment and problem-focused coping. This finding was unexpected as more apparent disability would be expected to motivate women to engage in more overt coping actions. The WHODAS is a measure of disability linked to any health condition, not specific to mental health problems. However, we have shown previously in this context that postpartum depressive symptoms are independent of physical health status indicators, such as low hemoglobin or low body mass index [76], and are strongly associated with functional impairment [58]. It is possible that aspects of problem-solving coping in this context were not captured adequately with the COPE scale; however, further studies are required to better understand this association.

\section{Limitations}

A limitation of this study is that we had not undertaken a formal cultural validation of the brief COPE for the local context. Nonetheless, the COPE was found to have reasonable construct validity in this sample. A further limitation is that it was not possible to elucidate the cause-effect relationship between depression and the coping strategies due to the cross-sectional nature of the study. A prospective study could help to elucidate whether coping strategies predispose women to depression or are a consequence of depression. The prognostic significance of particular coping strategies could also be investigated with a prospective design and would be an important evaluation of the predictive validity of the Brief COPE scale in this setting.

\section{Conclusion}

Religious coping was the most commonly used coping strategy by women with symptoms of postpartum depression in this rural Ethiopian community. Although it is not possible to know whether coping strategies lead to depression or vice versa, interventions can be developed that build on existing coping strategies and enhance the capacity of women to use more adaptive coping. The Brief COPE scale has fair internal consistency and acceptable construct validity but further cultural validation is needed.

\section{Additional file}

Additional file 1: Construct validity of brief COPE using confirmatory factor analysis. (DOCX $171 \mathrm{~kb}$ )

\section{Abbreviations}

AMOS: Analysis of Moment Structure; CFI: Comparative Fit Index; COPE: Coping Orientation for Problems Experienced; IRB: Institutional Review Board; LMIC: Low and Middle-Income Country; OSSS: Oslo Social Support Scale; PHC: Primary Health Care; PHQ: Patient Health Questionnaire; PPD: Postpartum Depression; PRIME: Program for Improving Mental Health care; RMSEA: Root Mean Square Error of Approximation; SEMI: Short Explanatory Model Interview; SNNPR: South Nations Nationalities and Peoples Region; TLI: Tucker Lewis Index; WHODAS: World Health Organization Disability Assessment Schedule 


\section{Acknowledgements}

We are grateful to the study participants for giving their time and energy to respond to the interview questions. The authors acknowledge the PRIME project for funding the research. The district health office, administrative office and the respective sub-districts are highly acknowledged for their cooperation in the process of the research. We also thank the data collectors, supervisors, and other members of the research team for their commitment to the study.

\section{Funding}

This study is an output of the PRogramme for Improving Mental health carE (PRIME). This work was supported by the UK Department for International Development [201446]. The views expressed do not necessarily reflect the UK Government's official policies.

\section{Availability of data and materials}

The data for this study are part of a PhD thesis for Telake Azale and therefore cannot be made publicly available at the present time. Through the PRIME consortium, data will be made publicly available in due course via applications through the PRIME website: www.prime.uct.za. The data are available on request from the corresponding author $(\mathrm{CH})$ for replication of the findings presented in this paper.

\section{Ethical considerations}

Ethical approval was obtained from the Institutional Review Board (IRB) of the College of Health Sciences, Addis Ababa University. Permission to conduct the research was received from the district Health and Administrative offices. Only women who gave written, informed consent to participate were included in the study.

\section{Authors' contributions}

TA developed the proposal, supervised the data collection process, developed the data entry template, checked the data entry periodically, analyzed the data, and prepared the draft manuscript. $\mathrm{CH}$ : supported development of the proposal, analyzed the data and contributed to interpretation of the findings, as well as commenting on the manuscript. AF: contributed to the development of the proposal including the translation of the instruments, helped in interpretation of the results and commented on the manuscript. GM: contributed to data analysis and commented on the manuscript. All of the authors proofread and approved the final manuscript.

\section{Ethics approval and consent to participate}

Ethical approval was obtained from the Institutional Review Board of the College of Health Sciences, Addis Ababa University. Permission was also obtained from the District Health Office. Women who agreed to participate gave written consent. For those who were not literate, independent witnesses were invited to sign to indicate that the information had been read out correctly. Non-literate participants then gave a finger print to indicate consent. Confidentiality was maintained by omitting identifiers from the computer and privacy was ensured during interview. Women who endorsed the PHQ item indicating suicidal ideation were linked to the nearby hospital psychiatric nurse-led outpatient clinic. All participants were given an information sheet and were only included in the study after providing informed and written consent.

\section{Consent for publication}

N/A

\section{Competing interests}

The authors declare that they have no competing interests.

\section{Publisher's Note}

Springer Nature remains neutral with regard to jurisdictional claims in published maps and institutional affiliations.

\section{Author details}

'University of Gondar, College of Medicine and Health Sciences, Department of Health Education and Behavioral Sciences, Gondar, Ethiopia. ${ }^{2}$ Addis Ababa University, Department of Psychiatry, School of Medicine, College of Health Sciences, 9086 Addis Ababa, PO, Ethiopia. ${ }^{3}$ King's College London, Institute of Psychiatry, Psychology and Neuroscience, Department of Psychological Medicine, Centre for Affective Disorders, London, UK. ${ }^{4}$ Addis Ababa University, Aklilu Lemma Institute of Pathobiology, Addis Ababa, Ethiopia.
${ }^{5}$ King's College London, Institute of Psychiatry, Psychology and Neuroscience, Centre for Global Mental Health, London, UK.

Received: 18 July 2017 Accepted: 29 January 2018

Published online: 08 February 2018

\section{References}

1. Shidhaye P, Giri P. Maternal depression: a hidden burden in developing countries. Ann Med Health Sci Res. 2014:4(4):463-5.

2. Fisher J, Cabral de Mello M, Patel V, Rahman A, Tran T, Holton S, Holmes W. Prevalence and determinants of common perinatal mental disorders in women in low- and lower-middle-income countries: a systematic review. Bull World Health Organ. 2012:90(2):139G-49G

3. Parsons CE, Young KS, Rochat TJ, Kringelbach ML, Stein A. Postnatal depression and its effects on child development: a review of evidence from low- and middle-income countries. Br Med Bull. 2012;101:57-79.

4. Surkan PJ, Kennedy CE, Hurley KM, Black MM. Maternal depression and early childhood growth in developing countries: systematic review and metaanalysis. Bull World Health Organ. 2011;89:608-15.

5. Medhin G, Hanlon C, Dewey M, Alem A, Tesfaye F, Lakew Z, Worku B, Aray M, Abdulahi A, Tomlinson M, et al. The effect of maternal common mental disorders on infant undernutrition in Butajira, Ethiopia: the P-MaMiE study. BMC psychiatry. 2010;10:32.

6. Stewart RC. Maternal depression and infant growth: a review of recent evidence. Maternal \& child nutrition. 2007;3(2):94-107.

7. Tomlinson M, Cooper PJ, Stein A. Post-partum depression and infant growth in a south African peri-urban settlement. Child Care Health Dev. 2006;32:81-6.

8. Ross J, Hanlon C, Medhin G, Alem A, Tesfaye F, Worku B, Dewey M, Patel V, Prince M. Perinatal mental distress and infant morbidity in Ethiopia: a cohort study. Arch Dis Child Fetal Neonatal Ed. 2011;96(1):F59-64.

9. Rahman A, labal Z, Bunn J, Lovel H, Harrington R. Impact of maternal depression on infant nutritional status and illness: a cohort study. Arch Gen Psychiatry. 2004;61(9):946-52

10. Deyessa N, Berhane Y, Emmelin M, Ellsberg MC, Kullgren G, Hogberg U. Joint effect of maternal depression and intimate partner violence on increased risk of child death in rural Ethiopia. Arch Dis Child. 2010:95(10):771-5.

11. Weobong B, Asbroek AH, Soremekun S, Gram L, Amenga-Etego S, Danso S, Owusu-Agyei S, Prince M, Kirkwood BR. Association between probable postnatal depression and increased infant mortality and morbidity: findings from the DON population-based cohort study in rural Ghana. BMJ. 2015;5

12. Patel V, DeSouza N, Rodrigues M. Postnatal depression and infant growth and development in low income countries: a cohort study from Goa, India. Arch Dis Child. 2003:88(1):34-7.

13. Black MM, Baqui AH, Zaman K, McNary SW, Le K, Arifeen SE, Hamadani JD, Parveen $\mathrm{M}$, Yunus $\mathrm{M}$, Black RE. Depressive symptoms among rural Bangladeshi mothers: implications for infant development. Journal of child psychology and psychiatry, and allied disciplines. 2007:48(8):764-72.

14. Hadley C, Tegegn A, Tessema F, Asefa M, Galea S. Parental symptoms of common mental disorders and children's social, motor and language development in sub- Saharan Africa. Ann Hum Biol. 2008;35(3):259-75.

15. WHO: Integrating mental health into primary care: a global perspective. In Geneva World Health Organization / World Organization of Family Doctors; 2008: 206.

16. WHO: mhGAP Mental Health Gap Action Programme: Scaling up care for mental, neurological, and substance use disorders. In.; 2008.

17. Misri S, Kostaras $X$, Milis $L$. The use of antidepressants in pregnancy and lactation. BCMJ. 2005;47(3):139-42.

18. Misri S, Kendrick K. Treatment of perinatal mood and anxiety disorders: a review. Can J Psychiatry. 2007;52(8):489-98.

19. Chowdhary N, Sikander S, Atif N, Singh N, Ahmad I, Fuhr DC, Rahman A, Patel $\mathrm{V}$. The content and delivery of psychological interventions for perinatal depression by non-specialist health workers in low and middle income countries: a systematic review. Best practice \& research Clinical obstetrics \& gynaecology. 2014;28(1):113-33.

20. Clarke K, King M, Prost A. Psychosocial interventions for perinatal common mental disorders delivered by providers who are not mental health specialists in low- and middle-income countries: a systematic review and meta-analysis. PLoS Med. 2013;10(10):e1001541.

21. Rahman A, Fisher J, Bower P, Luchters S, Tran T, Yasamy MT, Saxena S, Waheed W. Interventions for common perinatal mental disorders in women 
in low- and middle-income countries: a systematic review and metaanalysis. Bull World Health Organ. 2013;91(8):593-6011.

22. Folkman S. Personal control and stress and coping processes: a theoretical analysis. J Pers Soc Psychol. 1984;46:839-52.

23. Carver CS, Scheier MF, Weintraub JK. Assessing coping strategies: a theoretically based approach. J Pers Soc Psychol. 1989;56(2):267-83.

24. Scheier MF, Matthews KA, Owens J, Magovern GJS, Lefebvre RC. Dispositional optimism and recovery from coronary artery bypass surgery: the beneficial effects on physical and psychological well-being. J Pers Soc Psychol. 1989;57:1024-40.

25. Bjorklof GH, Engedal K, Selbaek G, Kouwenhoven SE, Helvik AS. Coping and depression in old age: a literature review. Dement Geriatr Cogn Disord. 2013;35(3-4):121-54

26. Orzechowska A, Zajaczkowska M, Talarowska M, Galecki P. Depression and ways of coping with stress: a preliminary study. Medical science monitor : international medical journal of experimental and clinical research. 2013;19:1050-6.

27. Billings $\mathrm{AG}, \mathrm{Moos} \mathrm{RH}$. Coping, stress, and social resources among adults with unipolar depression. J Pers Soc Psychol. 1984;46(4):877-91.

28. Wong DF. Stage-specific and culture-specific coping strategies used by mainland Chinese immigrants during resettlement in Hong Kong: a qualitative analysis. Soc Work Health Care. 2002;35(1-2):479-99.

29. See CM, Essau CA: Coping strategies in cross-cultural comparison. In: Psychologie-Kulter-Gesellschaft VS Verlag für Sozialwissenschaften; 2010.

30. Podolska MZ, Majkowicz M, Sipak-Szmigiel O, Ronin-Walknowska E. Ways of coping in stressful situations and anxiety-state or anxiety-trait among women with symptoms of perinatal depression. Ginekol Pol. 2009;80(3):201-6.

31. Demyttenaere $K$, Bonte L, Gheldof M, Vervaeke M, Meuleman C, Vanderschuerem D, D'Hooghe T. Coping style and depression level influence outcome in in vitro fertilization. Fertil Steril. 1998;69(6):1026-33.

32. Gutierrez-Zotes A, Labad J, Martin-Santos R, Garcia-Esteve L, Gelabert E, Jover M, Guillamat R, Mayoral F, Gornemann I, Canellas F, et al. Coping strategies for postpartum depression: a multi-centric study of 1626 women. Archives of women's mental health. 2015;

33. Gourounti K, Anagnostopoulos F, Lykeridou K. Coping strategies as psychological risk factor for antenatal anxiety, worries, and depression among Greek women. Archives of women's mental health. 2013;16:353-61.

34. Faisal-Cury A, Tedesco JJ, Kahhale S, Menezes PR, Zugaib M. Postpartum depression: in relation to life events and patterns of coping. Archives of women's mental health. 2004;7(2):123-31.

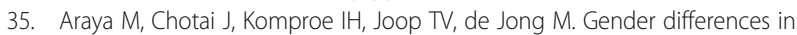
traumatic life events, coping strategies, perceived social support and sociodemographics among postconflict displaced persons in Ethiopia. Soc Psychiatry Psychiatr Epidemiol. 2007:42:307-15.

36. CSA: Population Projection of Ethiopia for All Regions At Wereda Level from 2014-2017. In Edited by Agency CS Addis Ababa: Central Statistical Agency; 2013.

37. Lund C, Tomlinson M, De Silva M, Fekadu A, Shidhaye R. PRIME: a Programme to reduce the treatment gap for mental disorders in five lowand middle-income countries. PLoS Med. 2012;9(12)

38. Carver CS. You want to measure coping but your protocol's too long: consider the brief COPE. International journal of behavioral medicine. 1997; 4(1):92-100.

39. Yusoff N, Low WY, Yip CH. Reliability and validity of the brief COPE scale (English version) among women with breast cancer undergoing treatment of adjuvant chemotherapy: a Malaysian study. Med J Malaysia. 2010;65(1):41-4.

40. Cooper C, Katona C, Livingston G. Validity and reliability of the brief COPE in carers of people with dementia: the LASER-AD study. J Nerv Ment Dis. 2008; 196(11):838-43.

41. BACANLI H, SÜRÜCÜ M, ILHAN T: An Investigation of Psychometric Properties of Coping Styles Scale Brief Form: A Study of Validity and Reliability. Educational Sciences: Theory \& Practice 2013, 13(1).

42. Snell DL, Siegert RJ, Hay-Smith EJ, Surgenor LJ. Factor structure of the brief COPE in people with mild traumatic brain injury. J Head Trauma Rehabil. 2011;26(6):468-77

43. Muller L, Spitz E. Multidimensional assessment of coping: validation of the brief COPE among French population. L'Encephale. 2003;29(6):507-18.

44. Doron J, Trouillet R, Gana K, Boiche J, Neveu D, Ninot G. Examination of the hierarchical structure of the brief COPE in a French sample: empirical and theoretical convergences. J Pers Assess. 2014;96(5):567-75.

45. Mohanraj R, Jeyaseelan V, Kumar S, Mani T, Rao D, Murray KR, Manhart LE. Cultural adaptation of the brief COPE for persons living with HIV/AIDS in southern India. AIDS Behav. 2015;19(2):341-51.
46. Kapsou M, Panayiotou G, Kokkinos CM, Demetriou AG. Dimensionality of coping: an empirical contribution to the construct validation of the briefCOPE with a Greek-speaking sample. J Health Psychol. 2010;15(2):215-29.

47. Krägeloh CU. A systematic review of studies using the brief COPE: religious coping in factor analyses. Religions. 2011;2:216-46.

48. Kroenke K, Spitzer RL, Williams JB. The PHQ-9: validity of a brief depression severity measure. J Gen Intern Med. 2001;16(9):606-13.

49. Adewuya AO, Ola BA, Afolabi OO. Validity of the patient health questionnaire (PHQ-9) as a screening tool for depression amongst Nigerian university students. J Affect Disord. 2006;96(1-2):89-93.

50. Chen S, Chiu H, Xu B, Ma Y, Jin T, Wu M, Conwell Y. Reliability and validity of the $\mathrm{PHQ}-9$ for screening late-life depression in Chinese primary care. International journal of geriatric psychiatry. 2010;25(11):1127-33.

51. de Lima Osorio F, Vilela Mendes A, Crippa JA, Loureiro SR. Study of the discriminative validity of the PHQ-9 and PHQ-2 in a sample of Brazilian women in the context of primary health care. Perspectives in psychiatric care. 2009:45(3):216-27.

52. Gjerdingen D, Crow S, McGovern P, Miner M, Center B. Postpartum depression screening at well-child visits: validity of a 2-question screen and the PHQ-9. Ann Fam Med. 2009;7(1):63-70.

53. Zhong Q, Gelaye B, Fann JR, Sanchez SE, Williams MA. Cross-cultural validity of the Spanish version of PHQ-9 among pregnant Peruvian women: a Rasch item response theory analysis. J Affect Disord. 2014;158:148-53.

54. Weobong B, Akpalu B, Doku V, Owusu-Agyei S, Hurt L, Kirkwood B, Prince $M$. The comparative validity of screening scales for postnatal common mental disorder in Kintampo, Ghana. J Affect Disord. 2009; 113(1-2):109-17.

55. Hanlon C, Medhin G, Selamu M, Breuer E, Worku B, Hailemariam M, Lund C, Prince M, Fekadu A. Validity of brief screening questionnaires to detect depression in primary care in Ethiopia. J Affect Disord. 2015;186:32-9.

56. Lloyd KR, Jacob KS, Patel V, St Louis L, Bhugra D, Mann AH. The development of the short explanatory model interview (SEMI) and its use among primary-care attenders with common mental disorders. Psychol Med. 1998;28(5):1231-7.

57. WHO: WORLD HEALTH ORGANIZATION DISABILITY ASSESSMENT SCHEDULE (WHODAS-II). In. Switzerland: World health Organization; 2000.

58. Senturk V, Hanlon C, Medhin G, Dewey M, Araya M, Alem A, Prince M, Stewart R. Impact of perinatal somatic and common mental disorder symptoms on functioning in Ethiopian women: the P-MaMiE populationbased cohort study. J Affect Disord. 2012;136(3):340-9.

59. Dalgard OS, Dowrick C, Lehtinen V, Vazquez-Barquero JL, Casey P, Wilkinson G. Negative life events, social support and gender difference in depression: a multinational community survey with data from the ODIN study. Soc Psychiatry Psychiatr Epidemiol. 2006;41:444-51.

60. Fekadu A, Medhin G, Selamu M, Hailemariam M, Alem A, Giorgis TW, Breuer E, Lund C, Prince M, Hanlon C. Population level mental distress in rural Ethiopia. BMC psychiatry. 2014;14:194.

61. Skinner EA, Edge K, Altman J, Sherwood H. Searching for the structure of coping: a review and critique of category Systems for Classifying Ways of coping. Psychol Bull. 2003;129(2):216-69.

62. Hooper D, Coughlan J, Mullen MR. Structural equation modelling: guidelines for determining model fit. The Electronic Journal of Business Research Methods. 2008;6(1):53-60.

63. Kasi PM, Naqvi HA, Afghan AK, Khawar T, Khan FH, Khan UZ, Khuwaja UB, Kiani J, Khan HM. Coping styles in patients with anxiety and depression. ISRN Psychiatry. 2012;2012:128672.

64. Abernethy AD, Chang HT, Seidlitz L, Evinger JS, Duberstein PR. Religious coping and depression among spouses of people with lung cancer. Psychosomatics. 2002;43(6):456-63.

65. Rahnama P, Javidan AN, Saberi H, Montazeri A, Tavakkoli S, Pakpour AH, Hajiaghababaei M. Does religious coping and spirituality have a moderating role on depression and anxiety in patients with spinal cord injury? A study from Iran. Spinal Cord. 2015;

66. Carpenter TP, Laney T, Mezulis A: Religious coping, stress, and depressive symptoms among adolescents: a prospective study. Psychology of Religion and Spirituality 2011

67. Pargament Kl, Koenig HG, Perez LM. The many methods of religious coping: development and initial validation of the RCOPE. J Clin Psychol. 2000;56:519-43.

68. Hebert $R$, Zdaniuk B, Schulz R, Scheier M. Positive and negative religious coping and well-being in women with breast cancer. J Palliat Med. 2009;12(6):537-45. 
69. Koenig HG, Cohen HJ, Blazer DG, Pieper C, Meador KG, Shelp F, Goli V DiPasquale B. Religious coping and depression among elderly, hospitalized medically ill men. Am J Psychiatry. 1992;149(12):1693-700.

70. Erulkar A. Early marriage, marital relations and intimate partner violence in Ethiopia. Int Perspect Sex Reprod Health. 2013;39(1):6-13.

71. Hailemariam M, Fekadu A, Prince M, Hanlon C. Engaging and staying engaged: a phenomenological study of barriers to equitable access to mental healthcare for people with severe mental disorders in a rural African setting. Int J Equity Health. 2017;16(1):156.

72. Rodriguesa M, Patel V, Jaswal S, de Souza N. Listening to mothers: qualitative studies on motherhood and depression from Goa, India. Soc Sci Med. 2003;57:1797-806.

73. Hanlon C, Whitley R, Wondimagegn D, Alem A, Prince M. Postnatal mental distress in relation to the sociocultural practices of childbirth: an exploratory qualitative study from Ethiopia. Soc Sci Med. 2009:69:1211-9.

74. Lee H, Yoon JY, Kim I, Jeong YH. The effects of personal resources and coping strategies on depression and anxiety in patients with chronic obstructive pulmonary disease. Heart \& lung : the journal of critical care. 2013:42(6):473-9.

75. Salabifard S, Rafezi Z, Haghighatbayan A. The relationship between coping strategies and marital conflict on employed women and housewives and compared these two groups. Jurnal UMP Social Sciences and Technol Manag. 2015;3(3)

76. Smartt C, Medhin G, Alem A, Patel V, Dewey M, Prince M, Hanlon C. Fatique as a manifestation of psychosocial distress in a low-income country: a population-based panel study. Trop Med Int Health. 2016;21(3):365-73.

\section{Submit your next manuscript to BioMed Central} and we will help you at every step:

- We accept pre-submission inquiries

- Our selector tool helps you to find the most relevant journal

- We provide round the clock customer support

- Convenient online submission

- Thorough peer review

- Inclusion in PubMed and all major indexing services

- Maximum visibility for your research

Submit your manuscript at www.biomedcentral.com/submit 